\title{
An empirical analysis of on-demand ride-sharing and traffic congestion
}

\author{
Ziru Li \\ Arizona State University \\ ziruli@asu.edu
}

\author{
Yili Hong \\ Arizona State University \\ ykhong1@asu.edu
}

\author{
Zhongju Zhang \\ Arizona State University \\ zhongju.zhang@asu.edu
}

\begin{abstract}
On-demand ride-sharing, as one of the most representative sectors of sharing economy has received a lot of attention and significant debate. Limited conclusive empirical research has been done to investigate the social welfare of such service. In this research, we conduct difference-in-difference analysis to examine the impact of Uber, an on-demand appbased ride sharing service, on urban traffic congestion. We find that after Uber entry, congestion of this area has been reduced significantly. In order to check the robustness of the results, we conduct instrumental variable analysis, additional analysis using alternative measures. Findings of this research will contribute to IS community by enriching the literature of digital infrastructure platforms. Practical insights derived from this research will help inform policy makers and regulators.

Keyword: digital platforms, ride-sharing services, sharing economy, traffic congestion
\end{abstract}

\section{Introduction}

Sharing economy is an emerging explosive trend equipped with the newest information technologies. The concept was first articulated when the Harvard law professor published a paper suggesting that we share goods in the economic process [1]. Many studies subsequently explored the potential of the collaborative consumption [2]-[6]. In 2011, TIME magazine named collaborative consumption one of the "ten ideas that will change the world". According to Price Waterhouse Coopers, in the year 2015-2016, sharing economy sectors generate $\$ 15 \mathrm{bn}$ in global revenues.

The transformative force of the sharing economy business model, however, has also raised challenges for incumbent industries and regulators. Traditional mature industries such as hotel and automotive industries were disrupted because consumers now have convenient and cost efficient access to resources without the financial, emotional, or social burdens of ownership [7]. As the popularity of sharing economy grows, it also raised debates on regulatory and safety concerns [8], [9]. Many traditional companies have flocked to regulators and politicians, and lobbied them to stop the growth of the sharing economy [10].

The debate over the sharing economy continues to unfold: advocates view Uber services as an important complement to the existing modes of urban transportation. Others criticize that sharing economy platforms often restructure the nature of employment and circumvent regulations in order to maximize company benefits. Uber, for instance, hires drivers as "independent contractors" as opposed to "employees", so their basic rights as workers are not guaranteed.

The impact of Uber on urban traffic congestion is one of those hotly debated topics in the media. Traffic congestion has become a serious social problem as the population grows, especially in metropolitan areas. According to 2015 Urban Mobility Report, travel delays due to congestion caused drivers to waste more than 3 billion gallons of fuel and kept travelers stuck in their cars for nearly 7 billion extra hours -42 hours per rushhour commuter. Does Uber play a role in urban area traffic congestion? There are two countervailing arguments. On one hand, by providing more convenient, less expensive ride-sharing services, Uber diverts nondriving trips like walking, transit, or cycling to driving mode. Hence, Uber induces additional traffic volume and increases traffic congestion. On the other hand, as a car sharing service, Uber has the potential to reduce traffic by diverting trips otherwise made in private, single occupancy cars or taxis. New York Times and the Office of the Mayor in New York City all released some studies on this issue, but the findings are inconclusive. In summary, there is limited empirical evidence to validate arguments on either side without comprehensive data and rigorous research.

There is limited research in IS area to address the issues related to Sharing economy. As an answer to this call, in this study, we use a natural experiment approach, the introduction of the ride-sharing service into urban areas between 2010 and 2014, to empirically examine the impact of Uber on traffic congestion. This research design offers us an important advantage: Since the time of Uber entry into various urban areas is different, we can use a difference-in-difference method to investigate the causal effect of Uber's entry on traffic congestion. We combined data from multiple sources to conduct the analyses. The urban mobility report contains different 
elements of congestion data for each of the 101 urban areas in the United States from 1982 to 2014. Additionally, we conducted comprehensive due diligence research and collected the entry time of Uber from Uber's official website. To control the possible effects of other variables, we collected data on fuel cost, socio-economic characteristics of urban areas, characteristics of road transport systems such as the lane miles of road, a number of travelers, etc. In addition to DID model, we performed instrumental variable analyses and robustness check.

Our findings based on a difference-in-difference analysis suggest that the entry of Uber actually leads to a significant decrease in traffic congestion in urban areas. This study makes contributions to IS community by enriching platform literature. Sharing economy platform is an emerging trend and shares the similar nature with other digital infrastructure platforms. Our research tackles an ongoing debate and provides new evidence of the social benefits associated with the sharing economy. Additionally, this study contributes to the traffic literature, which has so far largely ignored the impact of the emerging on-demand ride-sharing services on urban traffic congestion.

The rest of the paper is organized as follows. After reviewing relevant literature on the sharing economy, digital platforms, and traffic congestion in Section 2, we develop our main hypothesis in Section 3. Section 4 describes the data and details our econometric specifications. We discuss the results as well as their implications in Section 5. Finally, Section 6 concludes.

\section{Related Literature}

\subsection{Sharing economy}

Leveraging the latest information technology, sharing economy platforms efficiently connect providers who have unused and underexploited assets with consumers who are willing to pay for it [10]. Early empirical studies investigated the impact of the emerging business models in traditional industries. For example, Zervas et al. estimate that each $10 \%$ increase in Airbnb supply results in a $0.37 \%$ decrease in monthly hotel room revenue [11]. Wallsten explores the competitive effects of ride-sharing on the taxi industry and finds that Uber's popularity decreases the consumer complaints per trip about taxi in New York and decreases specific types of complaints about taxi in Chicago [10]. Greenwood and Wattal find that Uber decreases the rate of alcohol-related motor vehicle homicides [12]. Burtch et al. examine how the entry of platforms influences rates of entrepreneurial activities [13]. Rayle et al. surveyed ride-sharing users in San
Francisco to investigate the difference of trips and user characteristics between taxi and on-demand ridesharing services [14]. The researchers highlighted that the impacts of ride sharing on overall vehicle miles traveled and traffic congestion are unclear.

\subsection{Digital infrastructure and platforms}

Digital infrastructure and platforms bring together people, information, and technology to support business practices, social and economic activities, research, and collective action in civic matters [15]-[18]. There has been extensive research on digital infrastructure and platforms. Here we review only a few recent studies on the effects of digital platforms. Seamans and Zhu investigate the impact of Craigslist on three different sides of newspaper markets: newspaper side, subscriber side and display-ad side [19]. Rhue examines the racial dynamics in the crowdfunding platform Kickstarter [20]. Chan and Ghose investigate whether the entry of Craigslist increases the prevalence of HIV [21]. Bapna et al. estimate the causal effect of one specific characteristic of an online dating website [22]. Burtch et al. examine both the antecedents and the consequences of the contribution process in a crowd-funding platform [23]. Greenwood and Agarwal find evidence on how the entry of matching platforms influences the incidence rate of HIV infection by race, gender, and socioeconomic status [24].

\subsection{Traffic congestion and car sharing}

Traffic congestion has been a central problem in the transportation literature [25], [26]. It occurs when the demand for space is greater than the available road capacity. Some pioneering studies have examined the impact of car sharing on traffic congestion. For example, Alexander and González explored how ridesharing influences traffic congestion using mobile phone data and found that under moderate to high adoption rate scenarios [27], ridesharing would likely have noticeable effects in reducing congested travel times. Survey research in San Francisco reveals that although ridesharing substitutes longer transit trips, it does complement transit [14]. Fellows and Pitfield point out that encouraging ride-sharing may reduce vehicle miles travelled [28]. Jacobson and King investigated the potential fuel savings in the US when ride-sharing policy was announced and found that if $10 \%$ cars were to have more than one passenger, it could reduce $5.4 \%$ annual fuel consumption [29]. Caulfield estimated the environmental benefits of ride-sharing in Dublin and found that $12,674 \mathrm{t}$ of $\mathrm{CO} 2$ emissions were saved by individual ride-sharing [30]. Fellows and Pitfield examined the potential of ride-sharing to alleviate 
congestion and pollution and found evidence of its impact on reduction in vehicle kilometers, an increase in average speeds and savings in fuel, accidents and emissions [28].

\section{Hypothesis Development}

We summarize five mechanisms through which ride-sharing services could influence urban traffic congestion. These mechanisms have been demonstrated and accessed in previous study and report.

First, ride-sharing will reduce the total numbers of cars on the road by having more than one person in the car. A recent survey found that occupancy levels for ride-sharing vehicles averaged 1.8 passengers in contrast to 1.1 passengers for taxis in the matched pair analysis [14].

Second, ride-sharing services like Uber provide lowcost alternatives to owning a car thus reduces car ownership. A recent survey ${ }^{1}$ of more than 4,500 shared mobility users in the seven study cities (Austin, Boston, Chicago, Los Angeles, San Francisco, Seattle and Washington, DC) also found that people who use more shared modes report lower household vehicle ownership and decreased spending on transportation. As shown in Figure 1 and Figure 2, people who used several transportation alternatives reported having fewer vehicles than other survey takers.

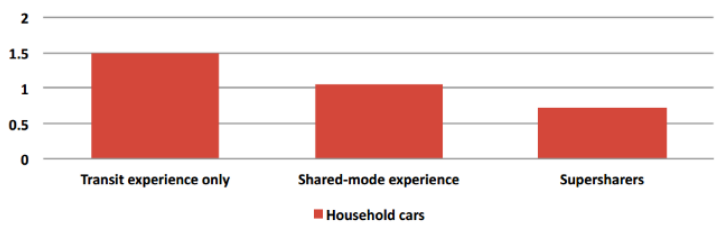

Source: APTA-Shared-Mobility Report Figure 1. Household vehicle ownership, by sharedmode experience

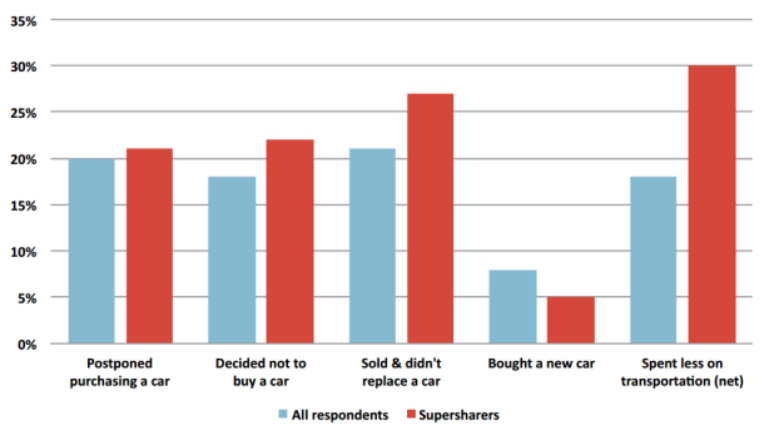

${ }^{1}$ This study was conducted for the American Public Transportation Association (APTA) by the Shared-Use Mobility Center http://www.apta.com/resources/reportsandpublications/Documents/A PTA-Shared-Mobility.pdf
Source: APTA-Shared-Mobility Report

Figure 2. Household and financial changes since starting to use shared modes-supersharers ${ }^{2} v$. all respondents

Many other studies also demonstrate the relationship between car-sharing services and car ownership [31][32].

Additionally, ride-sharing services can shift demand among different traffic modes. Traditionally, car sharing is effective in shifting the transition of transportation

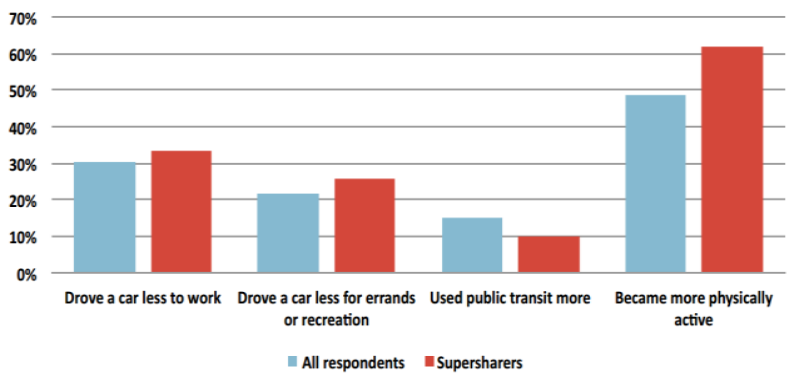

modes. Researchers found evidence that those who used car-sharing services drove significantly less than they did before they had used this service [34]-[36]. Martin and Shaheen found that more car sharing users increased their overall public transit and non-motorized modal use [32]. According to ATPA report (Figure 3), almost half of all respondents and nearly two-thirds of supersharers also say they are more physically active since they Source: APTA-Shared-Mobility Report

began using shared mobility options, which means car sharing helps divert more driving mode to non-driving mode.

Figure 3. Lifestyle changes since starting to use shared modes (net change)—supersharers v. all respondents

Fourth, Uber's surge pricing strategy has the potential to reduce traffic during peak hours. The idea behind surge pricing is to adjust prices of rides so as to match driver supply to rider demand at any given time. This demand-based pricing strategy is widely used in different industries. For example, it has been adopted by Disney Parks to reduce congestion and raise attendance at slower times. Airlines and hotels have also used similar tactics during busy holiday seasons. Despite the public outcry of the surge pricing mechanism, it has been shown that all stakeholders can benefit from it on a platform with self-scheduling capacity [37]. Since the core of this strategy is to equilibrate supply and demand, the price in peak hours can surge quite high, which in

\footnotetext{
${ }^{2}$ According to the study, "Supersharers" refers to people who routinely use several shared modes, such as bikesharing, carsharing (e.g. car2go or Zipcar), and ride sharing (e.g. Lyft or Uber)
} 
turn decreases the demand for services. It's, therefore reasonable to argue that when people are told that the current period is subject to surge pricing, they may delay their travel time or choose to use public transit instead.

Finally, Uber entry decreases traffic congestion and carbon emissions because it increases capacity utilization. In economies, capacity utilization means the extent to which available resources are being used at any given time. According to a study[38], in most cities, the efficiency of Uber is much higher than traditional taxis by having a higher fraction of time and a higher share of miles having fare-paying passengers in their backseats. Higher capacity utilization means the Uber drivers will spend less time wandering streets searching passengers, which otherwise will use up fuel and contribute to traffic congestions.

To conclude, in literature, there are solid empirical evidence that ride-sharing services will increase vehicles occupancy, reduce car ownership, shift traffic mode, delay or divert peak hour demand and increase capacity utilization. We expect that through these five mechanisms the entry of Uber into urban areas will reduce traffic congestion. Hence, we propose the following hypothesis:

HYPOTHESIS: Uber's entry into urban areas decreases the traffic congestion.

\section{Data and Methods}

\subsection{Research setting}

Uber is one of the most popular ride-sharing platform and the representative start-up of the sharing economy. By April 12, 2016, Uber was available in over 60 countries and 404 cities worldwide. The creative model of Uber has made it possible for people to simply tap their smartphone and have a cab arrive at their location in the minimum possible time. The whole process is extremely convenient. When the customer opens the app, they choose a ride (UberX, UberBlack, UberSUV and so on), set their location. The customer will see the driver's picture and vehicle details, and can track their arrival on the map. The pay process is "no cash, no tip, and no hassle". If the current time period is peak demand time, the customer will face surge pricing. But they are notified before making the decision. After that, the consumer can rate the driver and provide anonymous feedback about his/her trip experience.
In order to investigate the effect of Uber entry on urban area traffic congestion, we integrate the Uber entry time into major U.S. metropolitan areas, retrieved directly from the official Uber website, with congestion data from the Urban Mobility Report, provided by the Texas A\&M Transportation Institute (TTI). The Urban Mobility Report contains the urban mobility and congestion statistics for each of the 101 urban areas in the U.S. from 1982 to 2014. This report is acknowledged as the most authoritative source of information about traffic congestion and is widely used in the transportation literature. The comprehensive and longitudinal traffic-related data allow us to explore the change in urban traffic congestions due to external shocks (e.g. the entry of Uber). After merging the data sets, our final dataset comprises 957 observations spanning 11 years over 87 urban areas in the United States.

\subsection{Dependent variables}

In Urban Mobility Report, there are several performance measures for traffic congestion. We adopt all of them as the dependent variables in our analysis (as shown in Table 1.). The first one is the Travel Time Index (TTI). Many studies have used the TTI as a measure of traffic congestion [39]-[44]. In the Urban Mobility Report, the Travel Time Index refers to the ratio of travel time in the peak period to travel time at free-flow conditions. The Commuter Stress Index (CSI), another measure of traffic congestion, is the travel time index calculated for only the peak direction in each peak period. The CSI is said to be more indicative of the work trip experienced by each commuter on a daily basis and is thus adopted in this research as well. Both the TTI and the CSI are travel indices and do not represent the actual time of delay due to congestion. Hence we adopted the daily vehicle hours of delay to measure the amount of extra time spent traveling due to congestion. The Annual Delay per Auto Commuter is a measure of the extra travel time endured throughout the year by auto commuters who make trips during the peak period. In addition to the time dimension of traffic congestion, we also consider the value of the travel time delay, namely the congestion (or delay) cost. The total congestion cost takes into account of both the cost of delayed time and the cost of wasted fuel.

Table 2 describes the summary statistics of the dependent variables. It should be noted these variables are not normally distributed and the log transformations are used in our later analysis.

\subsection{Data}


Table 1. Description of dependent variables

\begin{tabular}{|l|l|}
\hline Dependent Variable & Description \\
\hline Travel Time Index (TTI) & The ratio of travel time in the peak period to travel time at free-flow conditions \\
\hline Delay Cost & Annual congestion cost total dollars(million) \\
\hline Delay Cost per auto & Annual congestion cost per auto commuter(\$) \\
\hline Delay Time & Annual hours of delay in thousand \\
\hline Delay Time per auto & Annual hours of delay per auto commuter \\
\hline Commuter Stress Index (CSI) & Travel time index calculated for only the peak direction in each peak period \\
\hline
\end{tabular}

Table 2. Summary statistics of dependent variables

\begin{tabular}{|l|l|l|l|l|l|}
\hline Variable & Obs & Mean & Standard Deviation & Min & Max \\
\hline CSI & 957 & 1.244681 & 0.1042578 & 1.07 & 1.64 \\
\hline Delay Cost (million) & 957 & 1552.794 & 2492.025 & 70 & 16346 \\
\hline Delay Cost per auto (dollars) & 957 & 6.688595 & 1.077973 & 4.248495 & 9.701738 \\
\hline Delay Time (in thousand) & 957 & 61401.17 & 99993.65 & 2035 & 630722 \\
\hline Delay Time per auto & 957 & 10.34483 & 1.098944 & 7.618251 & 13.35462 \\
\hline
\end{tabular}

\subsection{Control variables}

We control the effects of a number of variables including lane miles of road and the amount of travelers, which have been identified as important variables to explain traffic congestion in the transportation economic literature. Additionally, we control for the variables that may play a role in Uber's decision to enter different urban areas/cities. These variables include population size, socio-economic status (such as GDP, median income) of different urban areas. Table 3 summarizes the description statistics of the controls.

Table 3. Summary statistics of control variables

\begin{tabular}{|c|c|c|c|c|c|}
\hline Variable & Observations & Mean & Standard Deviation & Min & Max \\
\hline GDP & 957 & 119241.5 & 181231.5 & 3641 & 1423173 \\
\hline Population & 957 & 1820.846 & 2619.381 & 105 & 19040 \\
\hline Median Income & 957 & 48443.67 & 8163.061 & 32875 & 76165 \\
\hline Freeway lane miles & 957 & 16344.17 & 21505.79 & 480 & 139275 \\
\hline Arterial lane miles & 957 & 16103.52 & 20183.7 & 988 & 126010 \\
\hline Commuter(thousand) & 957 & 825.2027 & 976.1309 & 51 & 5928 \\
\hline Diesel Cost & 957 & 3.254242 & 0.6863275 & 1.77 & 4.91 \\
\hline Gasoline Cost & 957 & 2.921703 & 0.5604156 & 1.77 & 4.35 \\
\hline
\end{tabular}

\subsection{Empirical estimation}

As discussed earlier, the time of Uber's entry into various urban areas is different. Therefore, we use a difference-in-difference method to investigate the causal effect of Uber's entry on traffic congestion. Difference-in-Difference estimation has become an increasingly popular way to estimate causal relationships [45]. It is appropriate when one wants to compare the difference in outcomes after and before the intervention for the treated groups to the same difference for the untreated groups. In order to control the ex-ante differences between the heterogeneous urban areas, we include group fixed effects in our model specification. Specifically, we estimate the following regression equation:

$$
\begin{aligned}
& \ln \left(\text { Congestion Measures } \text { Me }_{\text {it }}\right) \\
& =\alpha+\delta\left(\text { Uber_Entry }_{i t}\right) \\
& +\lambda\left(\text { Controls }_{i t}\right)+\theta_{i}+\delta_{t}+\varepsilon_{i t}
\end{aligned}
$$

We run separate models for each of the dependent variables (Congestion Measures) described in Table 1. Controls $_{i t}$ represents measurements of variables described in Table 3 for urban area $i$ in year $t$. Uber entry is a dummy variable. It equals to 1 when the urban area $i$ has the Uber service in year $t$. The parameters $\theta$ and $\delta$ represent the time fixed effect and the urban area fixed effect. Fixed effects capture not only non-time varying factors but also allow the error term to be arbitrarily correlated with other explanatory variables, thus making the estimation results more robust. $\varepsilon$ is the error term. We use robust standard errors clustered at the urban areas to deal with potential issues of heteroscedasticity. 


\section{Results}

Table 4 summarizes our main results. Each column presents the effect of Uber entry as well as the effect of the control variables for a different measurement of traffic congestion. We included all control variables in eight models but did not report here. It can be seen that the effect of Uber entry is pretty consistent. The estimate of the effect (except on TTI and Excess fuel per auto) is significant and negative. We would like to highlight that the estimate of Uber entry on TTI is negative and the $p$ -value of the estimate is 0.12 , hence marginally significant given our sample size is only 957 with twoway fixed effects. The estimate of Uber entry on Excess fuel per auto is insignificant and positive $(p=0.615)$. Overall we find reasonable evidence that the entry of Uber significantly decreases traffic congestion in the urban areas of the U.S. (Hypothesis supported). It is also worth to note that as the median income in urban area increases, the traffic tends to get worse. This is consistent with the existing literature that traffic conditions in a city are usually associated with the overall economic activities.

\section{Additional analysis and robustness checks}

We then check all the possible interaction terms by including them into our model. But we find that none of the interaction terms is significant. We then conduct the following additional analysis and robustness checks.
In order to address the endogeneity problem, we conducted IV analysis with the unemployment rate as the instrumental variable. From the United States Bureau of Labor Statistics, we collected data on the unemployment rate of 87 urban areas from 2004 to 2014. This variable serves as a valid instrument because it should not be correlated with the traffic congestion of urban areas, but is an important factor for Uber executives to consider when deciding a go-to market strategy. One of the advantages of the sharing economy is that it provides flexible job opportunities that attract independent contractors to participate in the labor market. Hence, Uber may be well received in areas with higher unemployment rates.

Following Angrist and Pischke, we estimate the IV model with the 2SLS approach [46]. Especially, we estimate the probability of Uber entry time in each urban area using the standard linear probability approach and then included it in the second stage estimation. The results of this analysis are reported in Table 5, providing further empirical evidence of our main results. We further report the first stage results and the fit statistics in Table 6. It can be seen that there is a significant correlation between the IV and the Uber entry time ( $p=$ 0.018). Additionally, the first stage $F$ statistics are all significant. Finally, although the Cragg-Donald Wald F statistics is not very high, but they all pass Stock and Yogo's critical value [47]. Considering our sample size is relatively small $(\mathrm{n}=957)$, we conclude that the instrument variable, although a bit weak, is valid.

\subsection{Instrumental variables}

Table 4. Estimation results of Uber entry on traffic congestion

\begin{tabular}{|c|c|c|c|c|c|c|}
\hline & (1) & (2) & (3) & (4) & (5) & $(6)$ \\
\hline DV & TTI & CSI & Delay Cost & Delay Cos pa & Delay Time & Delay Time pa \\
\hline Uber Entry & $\begin{array}{c}-0.00237+ \\
(0.00151)\end{array}$ & $\begin{array}{c}-0.00377 * * * \\
(0.00139)\end{array}$ & $\begin{array}{l}-0.012 * * \\
(0.00600)\end{array}$ & $\begin{array}{c}-27.3 * * * \\
(7.271)\end{array}$ & $\begin{array}{l}-0.012 * * \\
(0.0059)\end{array}$ & $\begin{array}{l}-0.49 * \\
(0.252)\end{array}$ \\
\hline Controls & Included & Included & Included & Included & Included & Included \\
\hline Constant & $\begin{array}{c}0.745 * * * \\
(0.276)\end{array}$ & $\begin{array}{c}0.815 * * * \\
(0.286)\end{array}$ & $\begin{array}{l}-1.985 \\
(1.312)\end{array}$ & $\begin{array}{c}-7,35 * * * \\
(1,265)\end{array}$ & $\begin{array}{c}1.534 \\
(1.307)\end{array}$ & $\begin{array}{l}-42.70 \\
(45.01)\end{array}$ \\
\hline $\begin{array}{c}\text { Time and area fixed } \\
\text { effect }\end{array}$ & Yes & Yes & Yes & Yes & Yes & Yes \\
\hline Observations & 957 & 957 & 957 & 957 & 957 & 957 \\
\hline R-squared & 0.241 & 0.262 & 0.478 & 0.538 & 0.687 & 0.292 \\
\hline \# of Groups & 87 & 87 & 87 & 87 & 87 & 87 \\
\hline
\end{tabular}


Table 6. IV (Unemployment rate) - first stage analyses

\begin{tabular}{cc}
\hline DV & Uber entry \\
\hline Unemployment Rate & $0.019^{* *}$ \\
Control variables & $(0.327)$ \\
Time and urban area Fixed Effect & Included \\
F statistic & Yes \\
Observations & $5.61^{*}$ \\
Cragg-Donald Wald F statistic & 957 \\
\hline
\end{tabular}

Table 5. Estimation results using unemployment rate as the IV

\begin{tabular}{ccccccc}
\hline DV & $(1)$ & $(2)$ & $(3)$ & $(4)$ & $(5)$ & $(6)$ \\
TTI & CSI & Delay Cost & Delay Cost pa & $\begin{array}{c}\text { Delay Time } \\
\text { Delay Time } \\
\text { pa }\end{array}$ \\
\hline Uber Dummy & $-0.153^{* *}$ & $-0.168^{* *}$ & $-0.745^{* *}$ & $-821^{* *}$ & $-0.74^{* *}$ & $-30.8^{* *}$ \\
& $(0.0677)$ & $(0.0734)$ & $(0.327)$ & $(346.1)$ & $(0.327)$ & $(13.37)$ \\
Controls & Included & Included & Included & Included & Included & Included \\
Time and area fixed effect & Yes & Yes & Yes & Yes & Yes & Yes \\
Observations & 957 & 957 & 957 & 957 & 957 & 957 \\
R-squared & -9.152 & -10.210 & -6.134 & -7.092 & -3.281 & -11.107 \\
\# of Groups & 87 & 87 & 87 & 87 & 87 & 87 \\
\hline
\end{tabular}

\subsection{Alternative measure for Uber entry time}

To further check the robustness of the results, we use an alternative measure of Uber service in urban areas: the number of Uber searches in an urban area on Google Trends. Google Trends is a public web facility based on Google Search. From this website, we obtained data on how often a particular search item is entered relative to the total search volume across various regions of the world. Using Uber entry time as the proxy for the implementation of Uber service has limitations. After Uber enters into an urban area, people need time to accept and accustom to this new service. Uber entry may not represent the actual usage rate. There may exist a time lag between Uber entry and its impact on the traffic congestion. We used the search history of the keyword combination "Uber + the name of this urban area" to measure the popularity of Uber as well as the usage level in an urban area. It is noted that there may exist some other keyword combinations. It's reasonable to assume that when a person searches "Uber New York", he is interested and cares about the Uber service in the New York City. Figure 4 plots the search history of Uber service in Honolulu and its corresponding actual Uber entry time. We observe that even though Uber entered Honolulu in December 2013, it only began to become popular until some time later. . However, we noted that Uber entry time and the search volume on Google are positively correlated $($ Coeff $=0.7161$, sig $<0.0000)$. Hence we expect that the main results would be consistent when we use search history instead of entry time. 

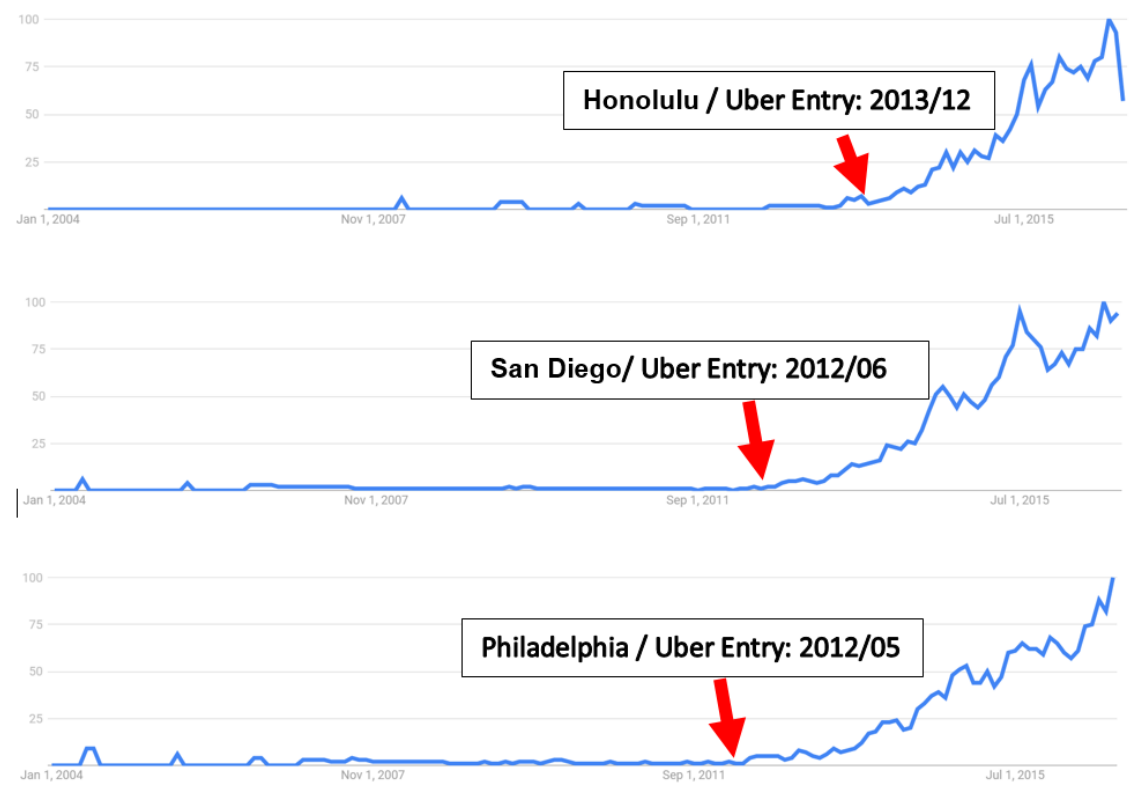

Figure 4. Search history of "Uber + sample urban areas" on Google Trends

There is, however, one issue with this variable. Before Uber actually entered an urban area, the search volume is generally not zero in most urban areas. The non-zero search volume could represent some expectations and curiosity but not the actual usage. We address this problem by multiplying it with the Uber entry dummy variable as a new variable: Uber usage. Tables 7 presents the results of our analysis using this new variable. We note that the results are similar, indicating that our estimation results are robust to alternative measures.

Table 7. Estimation results using alternative measure

\begin{tabular}{lcccccc}
\hline & $(1)$ & $(2)$ & $(3)$ & $(4)$ & $(5)$ & $(6)$ \\
\hline DV & TTI & CSI & Delay Cost & Delay Cost pa & Delay time & Delay time pa \\
Uber Usage & $-0.000421^{+}$ & $-0.000626^{* *}$ & $-0.00231^{* *}$ & $-4.817^{* * *}$ & $-0.00231^{* *}$ & $-0.0862^{*}$ \\
& $(0.000258)$ & $(0.000243)$ & $(0.00106)$ & $(1.286)$ & $(0.00106)$ & $(0.0434)$ \\
Constant & $0.744^{* * *}$ & $0.814^{* * *}$ & -1.991 & $7,363^{* * *}$ & 1.528 & -42.85 \\
& $(0.276)$ & $(0.286)$ & $(1.309)$ & $(1,261)$ & $(1.304)$ & $(44.96)$ \\
Controls & Included & Included & Included & Included & Included & Included \\
Time FE & Yes & Yes & Yes & Yes & Yes & Yes \\
Area FE & Yes & Yes & Yes & Yes & Yes & Yes \\
Observations & 957 & 957 & 957 & 957 & 957 & 957 \\
R-squared & 0.242 & 0.262 & 0.479 & 0.539 & 0.687 & 0.293 \\
\hline
\end{tabular}

Note: $* * * p<0.01,{ }^{* *} p<0.05, * p<0.1,{ }^{+} p<0.15$. Robust standard errors in parentheses.

\section{Conclusion}

Sharing economy platform, as one of the digital platforms, is becoming more and more overwhelming and changing human social life. It is thus important and incumbent to look into its potential impacts and implications. This paper studies one of the many social issues associated with ride sharing services. Specifically, we empirically examine how the entry of Uber into major U.S. metropolitan areas influences traffic congestions. By taking advantage of the different entry times of Uber into different urban areas, we are 
able to compare the difference in traffic congestion after and before Uber entry for the urban areas where Uber operates to the same difference for those urban areas without Uber service. We argue that ride-sharing service like Uber has the potential to reduce car ownership, shift traffic mode from single occupancy to ride-sharing, delay travel plans during peak hours, thus reducing the overall traffic congestion in an urban area. Using annual congestion data from the urban mobility report, we find empirical evidence to support this line of argument. Our results are consistent with instrumental variable analysis and robust to alternative measures. This study has several limitations. First, we identify a few mechanisms through which Uber decreases the traffic congestion. Data limitations prevent us from directly testing those hypotheses. We do want to highlight that the logics behind our argument have been tested in the transportation literature using survey data, mobile phone real time data, and simulations. Second, our traffic data is aggregated at the annual level. More granular level such as quarterly or monthly traffic data might allow us to pinpoint a more robust causal relationship. We are in the process to collect detailed traffic data to carry out further analysis. Finally, because the sharing economy is a relatively new phenomenon, we are unable to examine the longer term consequences of Uber's entry on traffic congestion. Future work using longer panel data is worth to pursue.

\section{References}

[1] Y. Benkler, "Coase's Penguin, or, Linux and" The Nature of the Firm,"” Yale Law J., pp. 369-446, 2002.

[2] M. Avital, M. Andersson, J. Nickerson, A. Sundararajan, M. Van Alstyne, and D. Verhoeven, "The Collaborative Economy: A Disruptive Innovation or Much Ado about Nothing?," in ICIS, 2014.

[3] R. Botsman and R. Rogers, What's mine is yours: how collaborative consumption is changing the way we live. Collins London, 2011.

[4] A. Felländer, C. Ingram, and R. Teigland, "Sharing Economy-Embracing Change with Caution," in Näringspolitiskt Forum rapport, 2015.

[5] A. Sundararajan, "From Zipcar to the sharing economy," Harv. Bus. Rev., vol. 1, 2013.

[6] A. Sundararajan, "Peer-to-peer businesses and the sharing (collaborative) economy: Overview, economic effects and regulatory issues," Writ. Testimony Hear.

Titled Power Connect. Peer Peer Businesses January, 2014.

[7] G. M. Eckhardt and F. Bardhi, "The Sharing Economy Isn't About Sharing at All," Harvard Business Review. [Online]. Available: https://hbr.org/2015/01/the-sharing-economy-isntabout-sharing-at-all. [Accessed: 31-Dec-2015].
[8] M. Feeney and R. companies Uber, "Is Ridesharing Safe?," Cato Policy Anal., vol. 767, p. 2, 2015.

[9] A. Malhotra and M. Van Alstyne, "The dark side of the sharing economy... and how to lighten it," Commun. ACM, vol. 57, no. 11, pp. 24-27, 2014.

[10] S. Wallsten, "The Competitive Effects of the Sharing Economy: How is Uber Changing Taxis?," Technology Policy Institute, Jun. 2015.

[11] G. Zervas, D. Proserpio, and J. Byers, "The rise of the sharing economy: Estimating the impact of Airbnb on the hotel industry," Boston U Sch. Manag. Res. Pap., no. 2013-16, 2014.

[12] B. N. Greenwood and S. Wattal, "Show Me the Way to Go Home: An Empirical Investigation of Ride Sharing and Alcohol Related Motor Vehicle Homicide," Available SSRN 2557612, 2015.

[13] G. Burtch, S. Carnahan, and B. N. Greenwood, "Can You Gig it? An Empirical Examination of the GigEconomy and Entrepreneurial Activity," Empir. Exam. Gig-Econ. Entrep. Act. March 7 2016, 2016.

[14] L. Rayle, S. Shaheen, N. Chan, D. Dai, and R. Cervero, “App-Based, On-Demand Ride Services: Comparing Taxi and Ridesourcing Trips and User Characteristics in San Francisco University of California Transportation Center (UCTC)," UCTCFR-2014-08, 2014.

[15] R. Adner and R. Kapoor, "Value creation in innovation ecosystems: How the structure of technological interdependence affects firm performance in new technology generations," Strateg. Manag. J., vol. 31, no. 3, pp. 306-333, 2010.

[16] Y. A. Au and R. J. Kauffman, "The economics of mobile payments: Understanding stakeholder issues for an emerging financial technology application," Electron. Commer. Res. Appl., vol. 7, no. 2, pp. 141164, 2008.

[17] P. Constantinides and M. Barrett, "Information Infrastructure Development and Governance as Collective Action," Inf. Syst. Res., vol. 26, no. 1, pp. 40-56, 2014.

[18] D. Tilson, K. Lyytinen, and C. Sørensen, "Research commentary-digital infrastructures: the missing IS research agenda," Inf. Syst. Res., vol. 21, no. 4, pp. 748-759, 2010.

[19] R. Seamans and F. Zhu, "Responses to entry in multisided markets: The impact of Craigslist on local newspapers," Manag. Sci., vol. 60, no. 2, pp. 476493, 2013.

[20] L. Rhue, "Who Gets Started on Kickstarter? Demographic Variations in Fundraising Success," 2015.

[21] J. Chan and A. Ghose, "Internet's dirty secret: assessing the impact of online intermediaries on HIV transmission," Chan J Ghose Internet's Dirty Secret Assess. Impact Online Intermed. HIV Transm. MIS Q., vol. 38, no. 4, pp. 955-976, 2013.

[22] R. Bapna, J. Ramaprasad, G. Shmueli, and A. Umyarov, "One-way mirrors and weak-signaling in online dating: A randomized field experiment," in International Conference on Information Systems 
(ICIS 2013): Reshaping Society Through Information Systems Design, 2013, vol. 3, pp. 2748-2762.

[23] G. Burtch, A. Ghose, and S. Wattal, "An empirical examination of the antecedents and consequences of contribution patterns in crowd-funded markets," Inf. Syst. Res., vol. 24, no. 3, pp. 499-519, 2013.

[24] B. N. Greenwood and R. Agarwal, "Matching Platforms and HIV Incidence: An Empirical Investigation of Race, Gender, and Socioeconomic Status," Manag. Sci., 2015.

[25] R. Cervero and M. Hansen, "Induced travel demand and induced road investment: a simultaneous equation analysis," J. Transp. Econ. Policy, pp. 469-490, 2002.

[26] P. B. Goodwin, "Empirical evidence on induced traffic," Transportation, vol. 23, no. 1, pp. 35-54, 1996.

[27] L. P. Alexander and M. C. González, Assessing the Impact of Real-time Ridesharing on Urban Traffic using Mobile Phone Data. Sydney, Australia, 2015.

[28] N. T. Fellows and D. E. Pitfield, "An economic and operational evaluation of urban car-sharing," Transp. Res. Part Transp. Environ., vol. 5, no. 1, pp. 1-10, 2000.

[29] S. H. Jacobson and D. M. King, "Fuel saving and ridesharing in the US: Motivations, limitations, and opportunities," Transp. Res. Part Transp. Environ., vol. 14, no. 1, pp. 14-21, 2009.

[30] B. Caulfield, "Estimating the environmental benefits of ride-sharing: A case study of Dublin," Transp. Res. Part Transp. Environ., vol. 14, no. 7, pp. 527-531, 2009.

[31] R. Cervero and Y. Tsai, "City CarShare in San Francisco, California: Second-Year Travel Demand and Car Ownership Impacts," Transp. Res. Rec. J. Transp. Res. Board, vol. 1887, pp. 117-127, Jan. 2004.

[32] E. W. Martin and S. A. Shaheen, "Greenhouse gas emission impacts of carsharing in North America," Intell. Transp. Syst. IEEE Trans. On, vol. 12, no. 4, pp. 1074-1086, 2011.

[33] R. Meijkamp, "Changing consumer behaviour through eco-efficient services: an empirical study of car sharing in the Netherlands," Bus. Strategy Environ., vol. 7, no. 4, pp. 234-244, 1998.

[34] P. Munheim, "Car Sharing Studies: An Investigation," Lucerne Switz., 1998.
[35] K. Steininger, C. Vogl, and R. Zettl, "Car-sharing organizations: The size of the market segment and revealed change in mobility behavior," Transp. Policy, vol. 3, no. 4, pp. 177-185, 1996.

[36] R. Katzev, "Car sharing: A new approach to urban transportation problems," Anal. Soc. Issues Public Policy, vol. 3, no. 1, pp. 65-86, 2003.

[37] G. P. Cachon, K. M. Daniels, and R. Lobel, "The role of surge pricing on a service platform with selfscheduling capacity," Available SSRN, 2015.

[38] J. Cramer and A. B. Krueger, "Disruptive Change in the Taxi Business: The Case of Uber," National Bureau of Economic Research, Working Paper 22083, Mar. 2016.

[39] R. Bertini, “'You are the traffic jam: an examination of congestion measures', Department of Civil and Environmental Engineering, Portland State University," Unpubl. Res. Monogr., 2005.

[40] Y. Hagler and P. Todorovich, Where high-speed rail works best. America 2050, 2009.

[41] T. Litman, "Evaluating rail transit benefits: A comment," Transp. Policy, vol. 14, no. 1, pp. 94-97, Jan. 2007.

[42] B. Mehran and H. Nakamura, "Considering travel time reliability and safety for evaluation of congestion relief schemes on expressway segments," IATSS Res., vol. 33, no. 1, pp. 55-70, 2009.

[43] M. N. Sweet and M. Chen, "Does regional travel time unreliability influence mode choice?," Transportation, vol. 38, no. 4, pp. 625-642, Apr. 2011.

[44] Y. Zhang, "Hourly Traffic Forecasts Using Interacting Multiple Model (IMM) Predictor," IEEE Signal Process. Lett., vol. 18, no. 10, pp. 607-610, Oct. 2011.

[45] M. Bertrand, E. Duflo, and S. Mullainathan, "How much should we trust differences-in-differences estimates?," National Bureau of Economic Research, 2002.

[46] J. D. Angrist and J.-S. Pischke, Mostly harmless econometrics: An empiricist's companion. Princeton university press, 2008.

[47] J. H. Stock and M. Yogo, "Testing for weak instruments in linear IV regression," Identif. Inference Econom. Models Essays Honor Thomas Rothenberg, 2005. 